\title{
Multidisciplinary Approach to Diagnose and Treat Diffuse Esophageal Leiomyomatosis: A Case Report
}

\author{
Luísa Martins Figueiredo', Maria Ana Rafael', Joana C. Branco ${ }^{1}$, Catarina G. Rodrigues ${ }^{1}$, António T. Alves ${ }^{2}$, David Horta ${ }^{1}$ and \\ Alexandra Martins ${ }^{1}$ \\ Departments of ${ }^{1}$ Gastroenterology and ${ }^{2}$ Pathology, Hospital Professor Doutor Fernando Fonseca, Amadora, Portugal
}

Diffuse esophageal leiomyomatosis (DEL) is a rare disorder that was first described in 1916. It is characterized by a circumferential thickening of the muscular layer of the esophageal wall and is known to be associated with nonspecific dysphagia. The causes of its incidence are unknown. While some cases of DEL are sporadic, two-third of the cases are reported in patients diagnosed with Alport Syndrome. DEL is also characterized by sensorineural loss of hearing, early cataract formation, and glomerulonephritis. The recommended treatment regimen for DEL generally consists of total esophagectomy, depending on the severity of the symptoms. ${ }^{1-4}$

Here, we describe the case of a 33-year-old Caucasian male patient with a 10 -year history of intermittent solid-food dysphagia. The reported case was not associated with significant weight loss or anorexia. The subject did not report of other symptoms such as regurgitation or chest pain. Due to his deteriorating condition, the patient sought consultation with a gastroenterologist in the previous year. Physical examination did not reveal anything abnormal and laboratory studies were also within the normal range. Esophagogastroduodenoscopy (EGD) revealed a submucosal bulge of more than $5 \mathrm{~cm}$, in the fundus of the stomach. This was suggestive of a subepithelial lesion or extrinsic compression and biopsies revealed no alterations. A computed tomography (CT) scan of the chest and abdomen showed marked irregular parietal thickening of the esophagus and cardia with about $12 \mathrm{~cm}$ of cranio-caudal extension and $6.2 \mathrm{~cm}$ in thickness. There was also dilatation of the upper regions of the esophagus. In the middle and proximal esophagus, another area with an enhanced degree of irregular parietal thickening was identified (Fig. 1A, B). The patient missed the subsequent consultations, and returned a year later with progressive worsening of symptoms. An EGD was repeated which mirrored findings of the previous one, indicating dilatation and tortuosity of the esophagus with several submucosal bulge areas (Fig. 2A, B). The patient underwent another CT that confirmed the previous findings. Endoscopic ultrasound (EUS) (Fig. 2C-E) showed a marked parietal thickening of almost the entire length of the esophagus, circumferential although asymmetrical, at the expense of the muscular layer itself, reaching a maximum of $25 \mathrm{~mm}$ in the axial view. This thickening extended to the cardia and gastric fundus, taking a nodular, hypoechogenic configuration, with a slightly heterogeneous echostructure, measuring $72 \times 40 \mathrm{~mm}$. EUS-guided biopsy from the cardiac and fundus lesion described it as a leiomyoma in the context of DEL that extended to the cardia and fundus of the stomach (Fig. 2F).

\footnotetext{
Received: April 23, 2020 Revised: May 6, 2020

Accepted: May 7, 2020

Correspondence: Luísa Martins Figueiredo

Department of Gastroenterology, Hospital Professor Doutor Fernando Fonseca, IC 19, Amadora 2720-276, Portugal

Tel: +351-91-736-1372, Fax: +351-21-434-8200, E-mail: Luisa_mmfigueiredo@hotmail.com

ORCID: https://orcid.org/0000-0002-5792-4947
}

(c) This is an Open Access article distributed under the terms of the Creative Commons Attribution Non-Commercial License (http://creativecommons.org/licenses/by$\mathrm{nc} / 3.0$ ) which permits unrestricted non-commercial use, distribution, and reproduction in any medium, provided the original work is properly cited. 

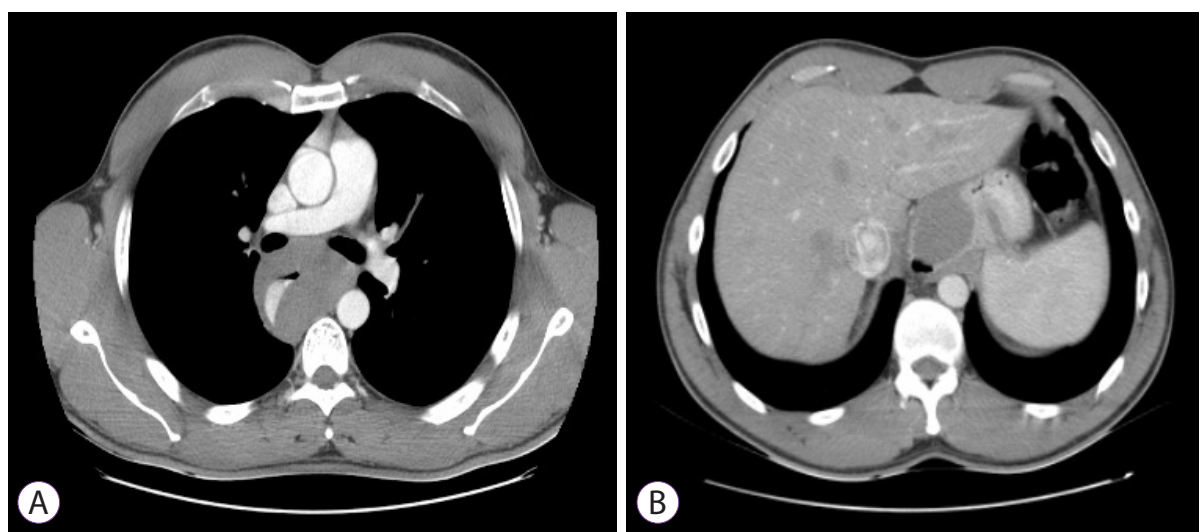

Fig. 1. (A, B) Computed tomography with marked nodular parietal thickening of the entire esophagus.
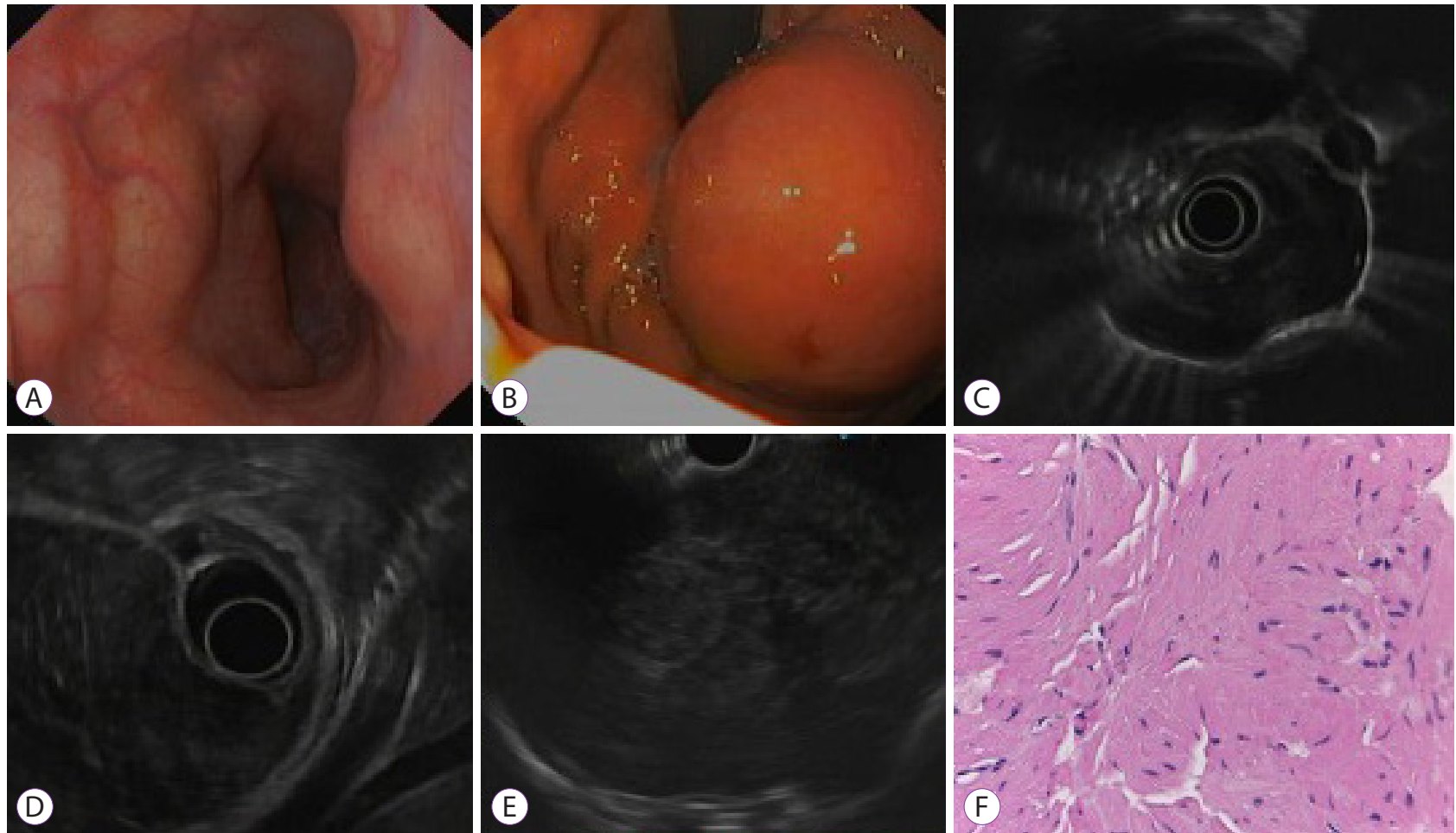

Fig. 2. (A) Esophagogastroduodenoscopy showing dilatation and tortuosity of the esophagus with several bulging areas of normal mucosa. (B) Esophagogastroduodenoscopy showing submucosal bulge in the fundus of the stomach. (C-E) Endoscopic ultrasound with parietal circumferential thickening of the esophagus, originating from muscular layer, extending to the cardia and gastric fundus. (F) Histologic examination showed proliferation of spindle-shaped cells, without atypia (hematoxilin-eosin, $\times 400$ ).

In a multidisciplinary meeting, it was decided that the patient would be kept under clinical and endoscopic surveillance.

This brief report depicts the rare imaging and endoscopic features of an exuberant form of DEL with pathologic correlation. Herein, we highlight the significance of undertaking a multidisciplinary approach in the diagnosis of such patients to determine the appropriate treatment regimen. 
Conflicts of Interest

The authors have no financial conflicts of interest.

Author Contributions

Conceptualization: David Horta

Data curation: António T. Alves

Supervision: Alexandra Martins

Writing-original draft: Luísa Martins Figueiredo

Writing-review\&editing: Maria Ana Rafael, Joana C. Branco, Catarina G. Rodrigues

\section{ORCID}

Maria Ana Rafael: https://orcid.org/0000-0001-9055-1399

Joana C. Branco: https://orcid.org/0000-0001-8733-6639

Catarina G. Rodrigues: https://orcid.org/0000-0002-4986-0891

António T. Alves: https://orcid.org/0000-0002-4142-8308
David Horta: https://orcid.org/0000-0002-6529-050X

Alexandra Martins: https://orcid.org/0000-0002-4807-9569

\section{REFERENCES}

1. Rapp JB, Ciullo S, Mallon MG. Diffuse esophageal leiomyomatosis: a case report with surgical correlation. Clin Imaging 2019;58:161-165.

2. Berenguer Francés M, Onrubia Pintado JA, Vázquez Pérez G. [Diffuse esophageal leiomyomatosis as a differential diagnosis of dysphagia]. Med Clin (Barc) 2016;147:377-378.

3. Ray S, Saluja SS, Gupta R, Chattopadhyay TK. Esophageal leiomyomatosis -- an unusual cause of pseudoachalasia. Can J Gastroenterol 2008;22:187-189.

4. Milito P, Asti E, Aiolfi A, Zanghi S, Siboni S, Bonavina L. Clinical outcomes of minimally invasive enucleation of leiomyoma of the esophagus and esophagogastric junction. J Gastrointest Surg 2020;24:499-504. 